\title{
Role of the Commission on Influenza
}

\author{
FRED M. DAVENPORT, M.D.
}

$S^{1}$ INCE 1940 the Commission on Influenza of the Armed Forces Epidemiological Board has been continuously engaged in investigations of influenza and has given special attention to the development of an effective method for prevention of this disease. The results of controlled field trials in 1943 and 1945 convincingly demonstrated the effectiveness of vaccination against influenza $\Lambda$ and influenza B. Vaccination studies in 1947 showed with equal authority that vaccines of limited antigenic coverage were ineffective against the $A^{\prime}$ variants prevalent that year and gave an unequivocal answer to the question, Are antigenic differences detected by laboratory methods of practical importance for immunization?

Despite the difficulty of conducting field trials in years of low influenza incidence, the results of studies carried out between 1949 and the spring of 1957 clearly demonstrated how to cope with the phenomenon of sudden major antigenic shifting. Vaccines containing the $A^{\prime}$ variant were repeatedly shown to be effective against influenza $A^{\prime}(1)$. During this period few studies on vaccine effectiveness were carried out under auspices other than those of the Commission on Influenza.

The vaccine trials have been only one of the commission's major functions. A chain of laboratories was established in 1942 . These are

Dr. Davenport, of the virus laboratory, department of epidemiology, University of Michigan School of Public Health, Ann Arbor, Mich., is director of the Commission on Influenza, Armed Forces Epidemiological Board. This article is based on a paper given at a symposium on Asian influenza held by the American College of Preventive Medicine and the health officers' section at the 1957 meeting of the American Public Health Association. still maintained to serve as listening posts for the early detection of influenza, to document its spread, and to provide virus samples to a central strain study center for antigenic analysis. This system has been continuously productive of valuable epidemiological information. For example, in 194:3 scattered local outbreaks of influenza $A$ were identified in the spring and early summer before the extensive epidemic began in November of that year. In 1945 , when the system was extended to include observations in most of the areas where the C.S. Army was engaged, a series of small outbreaks of influenza B, extending from March to the epidemic buildup in November and December, was traced in the United States and Alaska, in the Pacific and Caribbean theaters, and in Australia and South America. These observations revealed a year-long widespread prevalence of influenza B with a sharp fall and winter epidemic peak. The Army laboratories, and later the IVorld Health Organization, have continued and expanded this activity into a vast network so that by now the point-to-point spread of influenza can be rapidly and accurately followed, and the data can be viewed in historical perspective. The summer occurrence of Asian influenza was therefore not a new finding and in itself did not herald catastrophe.

\section{Development of Influenza Vaccines}

In addition to the laboratory observations, since 1942 studies made by the Commission on Influenza of the dimensions of antigenic variation of influenza viruses and their significance for immunity induced by vaccination or acquired by repeated infection have led to the recognition that the common antigenic components of influenza viruses provide a degree of cross resistance. The objective for prevention 
of influenza by vaccination has become the development of a vaccine of broad effectiveness containing representative strains of the major antigenic families of influenza viruses (2). It was natural then for the commission to be deeply interested and involved when Dr. Maurice R. Hilleman, then chief of the Respiratory Disease Division, Walter Reed Army Institute of Research, reported that another major antigenic shift had occurred and that the new viruses were responsible for the severe epidemics reported from the Orient in April and May of 1957 (3). Promptly, a number of steps were taken by the commission to assess the significance of these events.

On the basis of the first epidemiological and immunological information available, it seemed quite unlikely that vaccines used in former years would provide optimal protection against Asian influenza. In a series of conferences held first with military and later with civilian health authorities, a program was developed for primary immunization against the new antigenic variant, using monovalent vaccines of the highest potency obtainable-at that time 200 chicken cell agglutination (CCA) unitsto be followed in the military after a suitable interval by a booster dose of polyvalent vaccine containing the old as well as the new strains. The negotiations and the placing of a large order for vaccine by the military gave an essential impetus to vaccine production. Later, as part of the unprecedented effort directed by the Public Health Service in preparation for the current epidemic of Asian influenza in the civilian population, production of influenza vaccine was greatly expanded. Plans for effective use of vaccine were formulated, and successful methods were put into operation to maintain detailed surveillance of the spread and character of the influenza epidemic. These important developments comprise the most vigorous effort ever made to protect a population against influenza-the last great plague of mankind.

\section{Influenza Surveys}

In keeping with the traditions of the Armed Forces Epidemiological Board and its commissions, I made a reconnaissance early in June in Australia, the Philippines, Japan, and the
Hawaiian Islands to gain first-hand information from virologists, clinicians, and military and public health agencies about the impact of Asian influenza in these areas. At that time, when rumor was rife but facts were difficult to acquire, it was found that the disease was widespread although clinically mild. The influence of crowding on the incidence of Asian influenza was quite apparent. The influenza attack rate in Navy personnel stationed on ships was clearly higher than in those based on shore, who, like the personnel of the Army and the Air Force, had the benefit of a larger number of cubic feet of air space per man. The incidence of influenza was obviously higher in the lower socioeconomic groups of the countries visited, those groups who lived in closer proximity to each other than did their more fortunate neighbors. Moreover, it was learned that Australia had been seeded with influenza early in its winter season; yet no catastrophic epidemic had resulted. The influence, then, of cultural factors on the severity of epidemic influenza was again shown.

The fatalities in the Orient, reported in the press without appraisal, were found to be concentrated in the very young and in the old-age groups. Moreover, the attack rate by age followed the familar pattern, being highest in childhood and becoming progressively lower thereafter. Finally, considering the number of deaths reported and taking into account the number of persons ill, it was apparent that Asian influenza was not a particularly virulent form of infection. It was reassuring to learn that, despite an attack rate of about 30 percent, there had been no disruption of essential activities in either civilian or military communities.

Later, in August 1957, a field study was established in Santiago, Chile, to observe the effects of Asian influenza in a country which ordinarily has a high incidence of pneumonia during its winter season. Dr. Harold B. Houser was the field director of this special study group, and the members were selected from personnel of the Commission on Influenza, the Commission on Acute Respiratory Disease, and the Commission on Streptococcal Diseases, Armed Forces Epidemiological Board. Chilean investigators collaborated most effectively in this effort. 
The number of deaths from pneumonia occurring after influenza increased dramatically, but neither the case fatality rate nor the age distribution of pneumonia patients was different from other years-again there was no evidence of increased virulence of Asian influenza. There was just much more influenza, many more pneumonias, and hence a greater number of fatal cases of these diseases. In a careful study of about 50 fatal cases, it was found that approximately one-half showed evidence of staphylococcal pneumonia, while death in the remainder could largely be attributed either to overwhelming infection by organisms readily responding to early conventional treatment or to less intense infections in persons who had chronic disease involving vital organs. A small proportion of fatal cases were associated with infection in the last trimester of pregnancy. In a small number of cases the cause of death was recorded as hemorrhagic pneumonia, apparently without detectable secondary bacterial invasion. However, it was stressed that the pneumonia cases generally responded well to antibiotics.

The results of these field investigations were reported to the Surgeons General of the three armed services and to the Surgeon General of the Public Health Service. These reports served as timely and precise information to dispel rumor, to establish the pattern of the behavior of Asian influenza, and to forecast what might be encountered in the United States during the fall and winter of 1957-58.

\section{Virus Strains of Asian Influenza}

As time permitted, the question of the antigenic relationship of Asian strains to strains prevalent in former years was explored by studies carried out in the virus laboratory of the University of Michigan's School of Public Health at Ann Arbor. The information gained from the field trips and from other sources indicated that Asian influenza followed the familiar pattern of incidence by age outlined in former reports on the attack rate of influenza caused by strains similar to those of swine influenza (1918), by A strains (1943), and by $\mathbf{A}^{\prime}$ strains prevalent since 1947. The incidence of Asian influenza was highest in childhood and progressively lower in older age groups. The most plausible thesis yet presented to explain this phenomenon is that relative immunity in older persons is conferred not by highly strainspecific antibody but by a composite of antibodies built up by repeated exposure to other antigenic variants of influenza A (2). In consequence, then, persons having a composite antibody have a broad immunity to influenza even though their serums may show by conventional methods little or no hemagglutination inhibition (HI) antibody against the prevailing virus. To develop a composite antibody and a broad immunity by vaccination with several selected strains of virus has become one of the goals of the Commission on Influenza. It was important, therefore, to discover whether the relative resistance of older persons to Asian influenza could be correlated with detectable antibody.

The first significant report on the demonstration of antibody in the serums of normal humans came through Dr. Mulder from Leiden, Holland, who found respectable concentrations of antibody against Asian virus in the serums of a small proportion of persons 70-80 or more years of age (personal communication). This finding was promptly confirmed in Ann Arbor and elsewhere with serums obtained locally and, subsequently, with serums received from Dr. Mulder. Moreover, at Ann Arbor it was shown with pools of serums collected by 2-year age intervals that antibody detectable by complement fixation with Asian virus antigen was not present in persons below the age of 30 years but was usually present at low levels in those above 30 . In addition, by hemagglutination inhibition, using special treatment of serums and antigen, low levels of antibody were frequently found at ages corresponding to those at which high levels of $\mathbf{A}^{\prime}, \mathbf{A}$, and swine influenza virus antibodies are regularly present. There could be no doubt, then, that Asian virus was, antigenically speaking, not a completely "newe acquayantance."

This opinion was confirmed by observing the antibody response of four age groups to Asian virus vaccine given as $250 \mathrm{CCA}$ units in $1 \mathrm{ml}$. subcutaneously (table 1). For this presentation, antibody levels are expressed as the geometric mean value of the groups studied, using final dilutions of serums for the calculations. 
Table 1. Relation of age to antibody response after vaccination with 250 chicken cell agglutination units of Asian influenza virus

\begin{tabular}{|c|c|c|}
\hline Age group & Titer & $\begin{array}{c}\text { Frequency } \\
\text { of antibody } \\
\text { rise }^{1}\end{array}$ \\
\hline Childre & $2<32$ & \\
\hline Recruits. & $<32$ & $2 /$ \\
\hline Middle-aged persons & 32 & $11 / 2$ \\
\hline Persons over 80 years of age. & 281. 6 & $11 / 14$ \\
\hline
\end{tabular}

1 Numerator-number of persons showing antibody increase even when an increase was found only in the next highest dilution of serums; denominator-number of persons studied.

${ }_{2}$ Geometric mean postvaccination hemagglutination inhibition antibody titers. Prevaccination titers were less than 32 .

Children and military recruits showed no antibody increase as measured with the ferretmouse-egg line of Japan 305 strain; middleaged adults showed as a group antibody increase from less than 32 to 32 . Eleven of the twenty-five subjects studied showed some antibody increase. However, in a group of 14 persons 80 or more year's of age, antibody rose after administration of the same vaccine from less than 32 to 281.6 , and 11 of the 14 subjects showed antibody rise. Four of fifteen other senior citizens showed a rise in influenza antibody when raccinated with older strains.

In contradistinction to earlier explanations by other investigators, the accumulating epidemiological and immunological data strongly indicate that the high attack rate and ease of spread of Asian influenza do not reflect a total lack of immunity in the population. Rather, the data suggest that the capacity for rapid spread at high attack rates may be unrelated to the antigenic structure of the prevailing virus. This was certainly true when the $\Lambda^{\prime}$ strains emerged in 1946-47.

From the serologic findings in the current experience, correlations can be made between the resistance of very old persons to influenza and the presence of antibody that reacts with strains of Asian influenza. I)r. Mulder first suggested that the virus involved in the pandemic of 1890 was closely related to Asian strains, and our findings lend support to his hypothesis. More importantly, they suggest that antigenic variation among influenza vi- ruses has finite limits and that antigens formerly prominent are bound to be repeated as major antigenic components. 'This riew sup)ports the concept that ultimately a polyvalent composite vaccine can be given which will induce a broad immunity against influenza, an immunity that will no longer be jeopardized by sudden and unexpected antigenic shifting. The alternative is to pursue endlessly the futile course of trying with present methods to prepare a monovalent specific vaccine each spring to combat the unknown strain of influenza virus anticipated for the fall.

The Commission on Influenza was also concerned with defining the antibody response of humans to monovalent vaccines containing Asian virus because past experience had indicated that. while vaccination with the new strain was desirable for optimal protection, one could expect that antibody response and hence protection would not be optimal using the 200 CCA dose that was made the standard early in the summer. In brief, it seemed unlikely that an antigenic change in the strain would necessarily change immunological principles. Hence, owing to the increased yield of virus in eggs, as soon as vaccines could be prepared at higher unitage, studies were aimed at defining the dose-antibody response relationship in man to the virus of Asian influenza. The results of tests using vaccines prepared by 3 different pharmaceutical concerns by 3 different methods of manufacture are tabulated below.

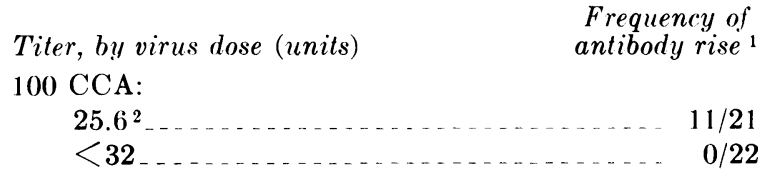

$200 \mathrm{CCA}:$

28.8

23.0

51.2

$11 / 21$

29.4 $16 / 25$

400 CCA:

83.2

35.2

750-800 CCA:

83.2

74.2

12 See footnotes 1 and 2 to table 1 .

Note: $\mathrm{CCA}=$ chicken cell agglutination. 
Serums were collected before and 2 weeks after subcutaneous vaccination with $1 \mathrm{ml}$. of vaccine. Clearly, the frequency of antibody increase and the amomnt of antibody stimulated by vaccine of 100 to $250 \mathrm{CCA}$ units were irregular and of low order. These poor results are like those observed in former studies when strains of influenza virus were given to persons who had not previously been exposed to these strains (f). With vaccines of $400 \mathrm{C}($. I mits and above, antibody increase was more uniform and the postracination levels were, in general, higher. These levels approach those found in the earliest successful field trials of vaccination carried out by the Commission on Influenza but are lower than the levels observed in recent years with vaccines of higher potency. The data also imply that doubling the dose of virus from 400 to $800 \mathrm{CCA}$ units does not commensurately increase the frequency or amount of antioody increase. Several members of the commission supervised the administration of most of these vaccines, collected the serums, and shipped them to the virus laboratory at $\mathrm{Am}$ Arbor so that comparisons could be made under uniform conditions. The data were available by late Iugust
1957 and were widely circulated. They supply one basis for the recent increase in potency of monovalent vaccine from 200 to $400 \mathrm{CCA}$ inits per dose.

\section{Effectiveness of Asian Influenza Vaccines}

The Commission on Influenza has now obtained the first specific information regarding the effectiveness of raccines of raried potency against the current epidemic of Asian influenza. They indicate that protection is increased as the dose of virus is increased.

The studies summarized in table 2 were begun as soon as influenza vaccines of desired potency could be obtained in sufficient quantity. On July 26, 1957, Dr. .J. O. Culver and Dr. Edwin H. Lennette began to inoculate 40 percent of the recruits newly assigned to training companies at Fort Ord. Calif., with monovalent Isian influenza virus vaccine containing 250 CC.L units per milliliter. One milliliter of vaccine was given subcutaneously in this and in the following studies. Sixty percent of the men in each company received a placebo injection of formalinized saline. It the time the

Table 2. Clinical efficacy of vaccines containing Asian strains of influenza virus

\begin{tabular}{|c|c|c|c|c|c|c|c|c|}
\hline \multirow{3}{*}{ Investigators } & \multirow{3}{*}{ Vaceine 1} & \multicolumn{3}{|c|}{ Vaccinated } & \multicolumn{3}{|c|}{ C'ontrols } & \multirow{3}{*}{$\begin{array}{c}\text { Esti- } \\
\text { mated } \\
\text { effective- } \\
\text { ness } \\
\text { (percent) }\end{array}$} \\
\hline & & \multirow{2}{*}{$\begin{array}{l}\text { Number } \\
\text { recruits }\end{array}$} & \multicolumn{2}{|c|}{$\begin{array}{l}\text { Cases of respira- } \\
\text { tory disease? }\end{array}$} & \multirow{2}{*}{$\begin{array}{l}\text { Number } \\
\text { recruits }\end{array}$} & \multicolumn{2}{|c|}{$\begin{array}{l}\text { Cases of respira- } \\
\text { tory disease }{ }^{2}\end{array}$} & \\
\hline & & & Number & $\begin{array}{c}\text { Rate } \\
\text { per } \\
1,000\end{array}$ & & Number & $\begin{array}{l}\text { Rate } \\
\text { per } \\
1,000\end{array}$ & \\
\hline $\begin{array}{c}\text { Culver and Lemnette, } \\
\text { Fort Ord, Calif. }\end{array}$ & $\begin{array}{l}250 \text { CCA units, } \\
\text { monovalent. }\end{array}$ & 916 & 20 & 21.8 & 1,448 & 55 & 37. 9 & 42 \\
\hline $\begin{array}{l}\text { Meiklejohn and asso- } \\
\text { ciates, Lowry Air }\end{array}$ & $\begin{array}{l}200 \text { CCA units, } \\
\text { monovalent. }\end{array}$ & 775 & 46 & 59.3 & 806 & 121 & 150. 1 & 61 \\
\hline Force Base, Colo. & $\begin{array}{l}400 \text { CCA units, } \\
\text { monovalent. }\end{array}$ & 649 & 12 & 17. 3 & 624 & 27 & 52.5 & 67 \\
\hline & $\begin{array}{l}\text { Polvvalent with } 400 \\
\text { CCA units, Asian. }\end{array}$ & 564 & 9 & & ${ }^{3} 614$ & 38 & & \\
\hline $\begin{array}{l}\text { Rose and associates, } \\
\text { Fort Dix, N.J. }\end{array}$ & $\begin{array}{l}200 \text { CCA units, } \\
\text { monovalent. }\end{array}$ & & 62 & & 1,665 & 126 & 76. 1 & 57 \\
\hline & & 1,665 & 29 & 17. 4 & & & & 77 \\
\hline $\begin{array}{l}\text { Gundelfinger and as- } \\
\text { sociates, Great }\end{array}$ & $\begin{array}{l}200 \text { CCA units, } \\
\text { monovalent. }\end{array}$ & 1,080 & 43 & & 1,444 & $2: 34$ & 162.0 & 75 \\
\hline $\begin{array}{l}\text { Iakes Naval Train- } \\
\text { ing Center, Ill. }\end{array}$ & $\begin{array}{l}\text { Polyvalent without } \\
\text { Asian strain. }\end{array}$ & 1,031 & 95 & 92.1 & & & & $4: 3$ \\
\hline
\end{tabular}

$1 \mathrm{C}(\mathrm{A}=$ chicken cell agglutination. $\quad 2$ Predominantly influenza, not serologically identified.

3 Type $B$ influenza vaccine. 
study was begun, Asian influenza was already prevalent at Fort Ord, and most of the patients with respiratory illness could not be admitted to the station hospital. Therefore, the effectiveness of the vaccine was measured by comparing the rate of dispensary visits for respiratory disease observed in the vaccinated and the rate in the unvaccinated populations. Cases of influenza occurring within 10 days after administration of vaccine or placebo were not considered in the evaluation because influenza was prevalent on the post at the time of vaccinating the recruits, and significant antibody increase would not be expected until 10 days after vaccination. For the period August 5-26 a rate of 21.8 cases of influenza per 1,000 recruits was found in the vaccinated group and a rate of 37.9 per 1,000 in the unvaccinated group, an estimated effectiveness of 42 percent.

At Lowry Air Force Base, Colo., Dr. Gordon Meiklejohn and his associates began their studies on July 29, 1957. Within 2 days, 775 airmen had received monovalent vaccine containing 200 CCA units per milliliter of an Asian strain of influenza isolated in Formosa. A placebo injection of formalinized saline was given to 806 airmen. The preparations were alternated within military units so that approximately 50 percent of the persons in each unit received virus vaccine and 50 percent, control material.

On September 23, a second study was established using three different influenza virus vaccines and a placebo preparation. In this study, 25 percent of the members of each unit received one of the following: $(a)$ monovalent vaccine containing 400 CCA units of Japan 305 strain, (b) polyvalent vaccine containing 400 CCA units of Japan 305, 200 CCA units each of swine (A-1931) and Great Lakes (B1954), and $100 \mathrm{CCA}$ units each of PR 8 (A-1934) and PR $301\left(\mathrm{~A}^{\prime}-1954\right),(c)$ influenza $B$ vaccine containing $400 \mathrm{CCA}$ units of the Great Lakes strain of 1954, or (d) formalinized saline. About 600 persons received each preparation. The concentration of Asian virus in these vaccines is probably higher than in the vaccines used at Fort Ord, since independent measurements have indicated that the commercial laboratory which, upon request, prepared the vaccine for Lowry Air Force Base usually underestimated the virus content of their product.

At the end of July, when vaccination was initially carried out at Lowry Air Force Base, there was no evidence of the presence of influenza, but the disease appeared in the third week of September. Dr. Meiklejohn and his associates have analyzed the admissions to the hospital for acute respiratory disease from September 16 to October 27 for those vaccinated with 200 CCA units of an Asian strain of influenza virus and for the control group. The approximate protective effect was 61 percent. In the second study, no significant differences in the occurrence of respiratory infections were observed between the groups inoculated on September 23 during the first 10 days after vaccination. However, in the subsequent period the approximate protective effect of vaccines containing 400 CCA units of Asian virus appears to be 67 percent. Note the apparent increased effectiveness of the more potent vaccines containing $400 \mathrm{CCA}$ units (table 2).

At Fort Dix, N. J., Dr. Harry Rose and his associates began vaccination of recruits on August 1, 1957, using two different vaccines. One contained 200 CCA units of Japan 305 strain per milliliter and the other, $750 \mathrm{CCA}$ units. Companies of recruits arriving at Fort Dix were divided into thirds by roster, and each group received either 200 CCA units of virus, 750 CCA units of virus, or formalinized saline. The vaccination program was completed on September 6. A sharp outbreak of Asian influenza occurred at the end of September. Dr. Rose has tabulated the hospital admission rates for respiratory disease in each vaccine group from September 29 through October 20. The rate per 1,000 in the control group was 76.1; in those receiving vaccine containing $200 \mathrm{CCA}$ units, 33.2; and in those receiving 750 CCA units, 17.4. The estimated effectiveness of the 200 unit vaccine was 57 percent and of the 750 unit vaccine, 77 percent. In this study, as in Dr. Meiklejohn's, the increased effectiveness of higher doses of virus for vaccination is clearly shown.

The Surgeon General of the U. S. Navy has provided information about the results of studies carried out at Great Lakes Naval Training Center, Ill., under the direction of Lt. 
Comdr. B. F. Gundelfinger, Jr. Vaccination of recruits was carried out on August 10, 1957, using two vaccines and a control material. The first vaccine contained 200 CCA units per milliliter of Japan 305 strain of influenza virus. The second vaccine, the Armed Forces 1956-57 polyvalent influenza vaccine, did not contain an Asian strain. This vaccine was composed of 250 CCA units each of swine, FM1, and Great Lakes strains. Thirty percent of the study population received monovalent vaccine, 30 percent received polyvalent vaccine, and 40 percent received placebo. Illness clinically diagnosed as influenza appeared at Great Lakes in epidemic proportions during the week ending October 5 and continued through the week ending October 19. In fact, the admission rate for the week ending October 12 was higher than the admission rate for any week during the past 8 years.

The average admission rate of recruits for the 3 weeks was 162.0 per 1,000 in the placeboinoculated group, 39.8 in the group receiving monovalent Asian virus vaccine, and 92.1 in the group receiving $1956-57$ polyvalent vaccine. In this short interval the effectiveness of the monovalent vaccine was approximately 75 percent and of the 1956-57 polyvalent vaccine about 43 percent. If the apparent protective effect of the polyvalent vaccine is substantiated when the studies are completed, this information will add to the data now at hand demonstrating important antigenic relationships between the Asian strains and other strains of influenza virus isolated in former years. This result encourages the outlook for a practical composite vaccine of broad coverage.

Although the studies reported in table 2 are incomplete, the trends shown are sufficiently distinct to indicate the final effects of vaccination with vaccines of various potencies. These effects should be increased when laboratory studies identify and remove from the study cases of illness caused by other respiratory disease agents which are so common in recruits. Results of the studies emphasize, too, that vaccine of $200 \mathrm{CCA}$ units gives somewhat less than optimal results, but that the effectiveness of vaccination can be increased by giving higher doses of virus.

\section{Summary}

This brief account of the role of the Commission on Influenza of the Armed Forces Epidemiological Board in studies of the epidemiology and prevention of influenza outlines the accomplishments of a group which has been working continuously and closely with the military since 1940 in the study of influenza as a disease problem. Largely by the efforts of this commission, the effectiveness of vaccination as a practical measure in preventing influenza has been firmly established, and the results of the commission's studies have given direction to the present effort to minimize the effects of epidemic Asian influenza.

Field studies conducted outside the United States on the incidence of Asian influenza in different age groups clearly showed the relative immunity of the older segments of the population to this disease. Laboratory studies carried out in Ann Arbor, Mich., and elsewhere have begun more clearly to define the antigenic relationships of current strains of influenza virus to older viruses and to demonstrate the antibody foundation of the relative immunity of the older age group. Field studies abroad also provided clinical, virologic, bacteriological, and pathological information on Asian influenza and its complications.

Finally, the results of the vaccine trials have provided the first specific evidence of clinical effectiveness of vaccine against the current epidemic of Asian influenza and have shown the value of increased dosages in providing more optimal protection against this disease.

\section{REFERENCES}

(1) Francis, T., Jr.: Current status of the control of influenza. Ann. Int. Med. 43 : 534 (1955).

(2) Davenport, F. M., Hennessy, A. V., and Francis, T., Jr.: Epidemiologic and immunologic significance of age distribution of antibody to antigenic variants of influenza virus. J. Exper. Med. 98 : 641 (1953).

(3) Meyer, H. M., Jr., Hilleman, M. R., Miesse, M. L., Crawford, I. P., and Bankhead, A. S.: New antigenic variant in Far East influenza epidemic 1957. Proc. Soc. Exper. Biol. \& Med. 95 : 609 (1957).

(4) Davenport, F. M., and Hennessy, A. V.: Predetermination by infection and by vaccination of antibody response to influenza virus vaccines. J. Exper. Med. 106: 835, Dec. 1, 1957. 